\title{
A Case of Pyrexia of Undetermined Origin
}

\author{
DEMONSTRATED AT THE ROYAL COLLEGE OF PHYSICIANS OF LONDON
}

British Medical fournal, 1974, 2, 157-161

The fifth of the quarterly clinicopathological conferences at the Royal College of Physicians was held on 25 October 1973. Dr. R. I. S. Bayliss took the chair, and introduced the case for discussion by saying that it was one of pyrexia of undetermined origin. P.U.O. was a challenge requiring for its elucidation the skill of the experienced physician, the detective work of a Sherlock Holmes, and the scientific precision of a Nobel prize winner. The possible causes varied from country to country, and indeed between parts of the same country. In India during the war the back of the temperature chart had a crib to tell one exactly what investigations should be done each day to elucidate a case of P.U.O. The present patient on the other hand had been in hospital for 20 weeks and no diagnosis had been established in life. So Professor Booth would face the bowling in the knowledge that the first ball would be a no-ball. He could square his shoulders and hit for a six.

\section{Clinical Summary}

HISTORY

Mrs. A. B. was a housewife aged 67 at the time of her death. Irish by birth, she had lived in London for many years and had never been abroad. For three hours daily she worked as an office cleaner. She had lived comfortably with her husband who was a commissionaire, and both had enjoyed a glass of Guinness. They had two children, and spent their holidays in a caravan in Devon.

The patient had been well until in December 1969 she fell downstairs and fractured her right wrist and left femoral neck. The Colles's fracture was treated with a plaster splint and the femoral neck by a Thomson's arthroplasty. Apart from the trauma, the only abnormal finding was a blood pressure of $180 / 90$, but there was no record of any cardiac murmur. In answer to direct questioning the patient said that during the previous 12 months she had had some intermittent vaginal bleeding, having had an uneventful menopause at the age of 50 . The patient was therefore seen by a gynaecologist and was re-admitted for investigation of this post-menopausal bleeding on 2 March 1970. She was found now to be running a pyrexia, had a pansystolic murmur at the apex of the heart, and a blood pressure of $160 / 100$. The only abnormality found at examination under anaesthetic was a urethral caruncle. This was considered to be the cause of her postmenopausal bleeding and it was cauterized. She continued to have a pyrexia and was seen by a physician who made a tentative provisional diagnosis of subacute bacterial endocarditis superimposed on an incompetent mitral valve.

She was transferred to a medical ward on 13 March 1970. Mrs. A. B. was then a rather wizened old lady weighing $45 \mathrm{~kg}$. Her only complaints were that she was somewhat tired and lethargic and sometimes experienced a low central backache. There was no history of weight loss.

The sole abnormality on physical examination was a pansystolic murmur at the mitral area of medium intensity (grade 4 out of 6), which was conducted to the axilla. The first and second heart sounds were normal. There was no splenomegaly or evidence of heart failure. The patient was febrile and throughout the 19 weeks she remained alive she ran a pyrexia which rose to $38.5^{\circ} \mathrm{C}\left(101^{\circ} \mathrm{F}\right)$ most evenings, falling to $37^{\circ} \mathrm{C}\left(98.8^{\circ} \mathrm{F}\right)$ in the mornings.

\section{INVESTIGATIONS}

The haemoglobin level was $11.9 \mathrm{~g} / 100 \mathrm{ml}$, falling to $8.9 \mathrm{~g}$ by the end of March.

This anaemia was normochromic and normocytic. The E.S.R. was persistently raised at $60-75 \mathrm{~mm}$ in 1 hour. The white cell count was $8,300-9,900$ per cu. mm. (polymorphs $85-90 \%$; lymphocytes $5-15 \%$; monocytes $1-5 \%$ without any abnormal cells). The platelet count was normal at 250,000 per cu. mm.

The blood urea was $41 \mathrm{mg} / 100 \mathrm{ml}$ and the electrolytes were always normal (plasma potassium $3.8 \mathrm{mM} /$ litre; sodium $133 \mathrm{mM} /$ litre). The total plasma protein concentration was $7.0 \mathrm{~g} / 100 \mathrm{ml}$ with $2.7 \mathrm{~g}$ albumin and $4.3 \mathrm{~g}$ globulin with an increase in alpha 1 and 2 components. A study of the immunoglobulins showed an increase in IgA and IgM. There was no paraprotein present nor Bence-Jones protein in the urine. The bilirubin level was $0.5 \mathrm{mg} / 100 \mathrm{ml}$ with 
an SGOT of 15 units and an SGPT of 10 units. The alkaline phosphatase was raised to 40-52 K.A. units (upper normal limit 17 units) with a 5-nucleotidase of 34 units (upper normal limit 18 units). The serum calcium was $9.4 \mathrm{mg} / 100 \mathrm{ml}$ and phosphorous $3.5 \mathrm{mg} / 100 \mathrm{ml}$.

Examination of the sputum on numerous occasions showed no pathogens or tubercle bacilli. Numerous midstream urine specimens were sterile with never more than four white cells per high power field but red cells were often found. A high vaginal swab was sterile. No ova, cysts, larvae, or pathogens were found in the faeces. Repeated blood cultures, aerobic and anaerobic, with and without the addition of carbon dioxide, were sterile.

Agglutination titres for Salmonella typhi and paratyphi B " $O$ " were less than 40; " $H$ " greater than 140; non-specific " $H$ " 40 . The titres for Brucella abortus (complete) were 160; incomplete 80 and for $B$. melitensis 160 on March 23. On 27 April the titre for $B$. abortus (complete) was 10 and incomplete was less than 20 , and for $B$. melitensis was 80 . The complement fixation test for brucella was negative on both occasions. The toxoplasma dye test was less than 1:64 on two occasions. The Q-fever complement fixation test was less than $1: 8$. The cytomegalovirus complement fixation antibody titre was $1: 32$.

No L.E. cells were found. The antinuclear factor was absent. The Mantoux test was negative at $1: 10,000$ and $1: 1,000$. The bone marrow showed non-specific myeloid hyperplasia with no abnormal cells; it was sterile on culture.

$X$-ray films of the chest, of the kidneys, and of the skeleton were normal, as was a barium meal and follow-through. The electrocardiogram was normal.

\section{PROGRESS}

On 16 April the patient developed diarrhoea without mucus but associated with the passage of some bright red blood and accompanied by generalized colicky abdominal pain. This episode subsided after a week without any specific treatment. The stools grew no pathogens; sigmoidoscopy to $14 \mathrm{~cm}$ was normal as was a barium enema. Subsequently the patient became weaker and mentally confused. $A$ brain scan and a liver scan were both normal. Under a single general anaesthetic cystoscopy, because of the microscopic haematuria, a liver biopsy and a scalene lymphnode biopsy were done. Nothing abnormal was found macroscopically or histologically.

On 27 April an orthopaedic colleague reported that he could find no evidence of low-grade osteomyelitis or infection around the hip prosthesis. By 2 May the patient had deteriorated further. She was increasingly disorientated and much weaker. The haemoglobin had fallen to $8.5 \mathrm{~g} / 100 \mathrm{ml}$. A transfusion of 4 units of blood was given. A 12-day course of tetracycline ( $2 \mathrm{~g}$ daily) had no influence on the pyrexia.

On 8 May a laparotomy was performed by Mr. Gerald Westbury. The spleen was soft and three times its normal size. No other abnormality was found after a most thorough search. The following day treatment with penicillin (six megaunits daily intravenously) for two weeks and streptomycin $0.75 \mathrm{~g}$ daily intramuscularly was started without effect on the patient's clinical state or the pyrexia.

Candida albicans $(10,000 / \mathrm{ml})$ was grown from the patient's urine on 18 May. This was associated with a candida antibody titre of $1: 320$ in the serum. Treatment with 5-fluorocytosine was given for the next four weeks without any apparent improvement. The fever and the cardiac murmur remained unchanged.

The patient now began to deteriorate more appreciably with marked anorexia : her weight had fallen to $32 \mathrm{~kg}$; she was drowsy, weak, confused, and incontinent of faeces and urine. The alkaline phosphatase was $18 \mathrm{~K}$.A. units. A course of ampicillin, $500 \mathrm{mg}$ four times a day for two weeks, had no effect on the fever. By 2 July the patient again complained of low midline backache. The E.S.R. was $73 \mathrm{~mm}$ in one hour; the haemoglobin $7 \cdot 5 \mathrm{~g} / 100 \mathrm{ml}$. The serum amylase was less than 130 Somogyi units. Glycosuria without ketonuria was noted. The blood glucose was $249 \mathrm{mg} / 100 \mathrm{ml}$ fasting; $339 \mathrm{mg}$ at 12 noon; and 204 $\mathrm{mg}$ at 7 p.m. The serum sodium was $140 \mathrm{mM} / 1$; potassium $3.0 \mathrm{mM} / 1$.; bicarbonate $37 \mathrm{mM} / 1$; urea $33 \mathrm{mg} / 100 \mathrm{ml}$.

The patient died on 15 July.

\section{Discussant's Comments}

PROFESSOR C. C. BOOTH (1): I frankly don't know what's wrong with this patient. The story starts with trauma. The fractures of the wrist and femoral neck were the first things that happened to this lady with apparent previously good health. In any diagnostic problem the initial event is often a clue to subsequent developments. In this sort of case one has to keep in mind the possibility of an infection in the bone that was operated on.

Reading on, the urethral caruncle was thought to be the cause of her postmenopausal bleeding, but did it stop after cautery?

DR. BAYLISS (2): It stopped clinically but we did later find microscopic haematuria from time to time.

PROFESSOR BOOTH: Did they do a dilatation and curettage at the same time?

DR. BAYLISS: They did and they found nothing.

PROFESSOR BOOTH: So it doesn't look as though she had a cancer of the cervix or body of the uterus. But she was then found to have a pyrexia and there was a pansystolic murmur at the apex of the heart. If you read William Evans's book on this he will tell you that many systolic murmurs at the apex are functional and can be ignored, but this one doesn't sound functional to me. It is a curious murmur in that it was apparently not present three months earlier, and occurred in a lady of 67 who had hypertension but had no cardiac enlargement on the chest $x$-ray film and had a normal E.C.G. That is not the murmur of chronic rheumatic heart disease. But the hunt was on for an infection causing subacute bacterial endocarditis. It is interesting that low central backache was a feature of her story from then on. She complained again before she died of low central backache.

Investigations did not reveal anything, but let me comment on some significant points. She had a normochromic normocytic anaemia, a feature that is common in infection, but she had a normal white count. The E.S.R. was persistently raised, indicating deepseated mischief. What was the eosinophil count? DR. BAYLISS: It was not abnormal.

PROFESSOR BOOTH: The blood urea was a little up and there was a non-specific increase in IgA and IgM, but no paraprotein or Bence-Jones protein in the urine. It is most interesting that the liver function tests were then abnormal. The alkaline phosphatase and 5-nucleotidase were moderately raised with a normal bilirubin. Later we see that laparotomy, scan, and biopsy showed a normal liver. So we can assume that these were functional liver abnormalities induced by whatever was causing the pyrexia. We know we can get abnormal liver function from infection of any cause. One is frequently asked, as a gastroenterologist, to see this sort of patient with a view to doing a liver biopsy. The other thing that can induce pyrexia and abnormal liver function tests is a hypernephroma.

Everybody was looking for infection, and tuberculosis is still a very possible cause of this. But no sign of that was found. Red cells were often found in the urine. The question here is whether they were coming from the lower urinary tract or from the kidney itself. Was there any proteinuria?

DR. BAYLISS: Traces from time to time.

\section{POSSIBLE DIAGNOSES}

PROFESSOR BOOTH: So there was no suggestion of renal disease, causing proteinuria. Now we find a whole series of tests looking for an infection. We don't know if she had had a T.A.B. injection to give these agglutination titres but they don't suggest active infection. The brucella titres are interesting, seeming to fall later on. This suggests that she had been exposed to brucella infection at some stage but it is unlikely that it was active now because the complement fixation test was negative on both occasions. Q-fever has to be thought of in apparent subacute bacterial endocarditis when you can't grow a bacterium, but coxiellae were not found. It is interesting that the Mantoux test was negative in a lady who had calcium present 
in the left upper zone of her lung. The right kidney was very low and there is another fleck of calcium there. These findings suggest to me that she had been exposed to tuberculosis.

Next, she had an episode of diarrhoea, which suggests one of two possibilities. With a murmur in the mitral area one might imagine that a bit of clot had been shot off and embolized in the gut which then completely recovered. Another alternative is that she might have had an intestinal lesion big enough to produce an intussusception, such as a small tumour of the small or large intestine, and this too could have completely corrected itself. I think the barium enema and the rather gentle sigmoidoscopy excludes active ulcerative colitis, or diffuse chronic inflammatory disease of the large bowel. I take it that her mental confusion was a toxic confusional psychosis in a lady with fever.

She then went progressively downhill. She was given tetracycline, presumably because it was still thought that she might have a rickettsial endocarditis. I must accept the report of normality at laparotomy from the surgeon concerned. The enlarged spleen does suggest an infective process but the lack of response to penicillin and streptomycin is against any of the normal bacterial infections. Then it seemed she had candidiasis, but I doubt that she had had this throughout.

In the last phase the alkaline phosphatase level is only slightly raised, and not as high as it might have been with an infiltrating lesion of the liver. The low midline backache recurred. Did she have cancer of the pancreas? She had a normal amylase but she did have glycosuria and raised blood glucose levels. Something had been happening in the pancreatic region. She died with a normal blood urea, which is very unusual in someone dying of subacute bacterial endocarditis.

What is the differential diagnosis ? I cannot put it all together into a diagnosis that completely satisfies me. I would start off with subacute bacterial endocarditis, which has not been supported by the blood cultures. I think everything is against this because the murmur appears to have occurred late on in life for the first time. Patients with this disorder do not usually die of bacterial endocarditis in a progressive decline but of heart failure or renal failure or progressive embolization. There was no clubbing, and she did not respond to any of the antibiotics. Rickettsial endocarditis remains on the cards but it is unusual in someone whose heart was apparently normal earlier on. A fungal endocarditis frequently produces large emboli involving large vessels; - there was only one possible one here, and there was no eosinophilia which most patients with fungal infections on a heart valve show.

The next thing is a left atrial myxoma, which can produce fever and curious murmurs. But the murmurs vary and death usually occurs suddenly, either from emboli or from obstruction to the left side of the heart. This diagnosis would not explain the progression of the disease, the pain in the back, or the termination with glycosuria.

What about tumours? The basic diagnosis must be either infection or tumour. If it is a cumour, one possibility is cancer of the pancreas. I am worried about the surgeon missing that. The murmur could then have been caused by non-bacterial or marantic endocarditis. The other tumour to be thought of is a hypernephroma, and was the uterus entirely normal? Low backache could result from cancer of the uterus but I think this unlikely. What about other infections? We must still consider tuberculosis as a possibility, though the fever did not respond to streptomycin.

To summarize, I doubt that this was an example of primary subacute bacterial endocarditis. I think the fungal infection was probably terminal, and I would put forward the following possibilities. As a long shot tuberculosis with an unimportant murmur that was mistakenly thought to be significant in a hypertensive lady; a tumour of some sort, either a pancreatic carcinoma with marantic endocarditis, or possibly a tumour of the kidney. And finally, if she had something other than pancreatic carcinoma, we would need to explain the terminal hyperglycaemia, perhaps a piece of clot shot off in that direction too. I shall be very interested to know what was found.

\section{Clinical Comments}

SIR JOHN MCMICHAEL (3): She got her two fractures from one fall about six months before her death. Did they heal properly or were they pathological ?

DR. BAYLISS: They were ordinary straightforward fractures and healed perfectly well.

DR. J. H. WALTERS (4): Were $x$-ray films taken of the lumbar spine to seek a cause for her low backache?

DR. BAYLISs: Yes, they showed just the amount of degenerative osteoarthritis you would expect in a lady of this age, but no osteomyelitis.

DR. J. HARMAN (5): Professor Booth has brushed off these liver function tests by saying that the liver was pretty sickwhich was not surprising as the whole patient was pretty sick. Would he go further and agree with me in the view that liver function tests are seldom valuable and have frequently led many people astray and that medicine would be better without them?

PROFESSOR BOOTH: I don't think I can agree with that. They are spendid when properly interpreted.

DR. M. NELLEN (6): Professor Booth quoted Dr. Evans's book, published about 20 years ago, that systolic murmurs at the apex may be meaningless. In the last ten or 15 years these murmurs have been elucidated considerably. We know that a systolic murmur in a woman at this age can often be associated with infective endocarditis with negative blood cultures and can go on chronically. I think it is very difficult to say this woman did not have it, and a fungal endocarditis is very much on the cards.

DR. D. W. PUGH (7): Do we know if coxsackie virus studies were done? These are considered a possible cause of the increase of diabetes in young people and also cause myocarditis. Did the E.C.G. change the last few weeks?

DR. BAYLISS: The. E.C.G. did not change. We didn't do coxsackie studies, partly because we didn't think of them, and so often the results come back when the patient is well or dead.

I would like to add one or two more points before the denouement. The spleen was enlarged at laparotomy, but the patient was given four pints (21.) of blood some days beforehand and the splenic enlargement was possibly due to that. The terminal blood urea of $33 \mathrm{mg} / 100 \mathrm{ml}$ was a credit to the devoted nursing she had, which gave her adequate fluids though she was comatose. The pain in the back was lower than the usual area for pancreatic referral. Finally, the summary that went with her body to the necropsy room read-"The diagnosis, unfortunately, despite this length of time in hospital, is still P.U.O. We have a strong suspicion of a carcinoma of the pancreas. We find it hard to believe that she did not have subacute bacterial endocarditis and there was evidence to support candida as the cause of this." Dr. Branfoot will now tell you the results of the necropsy.

\section{Pathological Findings}

DR. A. C. BRANFOOT (8): The body was that of a small elderly wasted woman with a recent upper paramedian abdominal scar, and an older longitudinal scar over the left greater trochanter. There was no sign of infection at the site of that prosthesis.

In the skull the only abnormality was a small meningioma in the left lateral sinus. In the thorax the pleural sac was obliterated by old fibrous adhesions. The trachea and bronchi contained a lot of mucopus and were cylindrically dilated right out to the pleura-a finding which one associates with chronic bronchitis. Histologically the bronchial glands were enlarged. The lungs were congested and oedematous but showed no sign of tuberculosis except for a small scar at the apex. She had an aspiration pneumonia in the upper lobes.

The pericardium contained a slight excess of fluid and there was a fibrinous exudate on the pericardial surfaces. The heart 
was enlarged with marked left ventricular hypertrophy. The coronary arteries were atheromatous but widely patent. The myocardium was healthy. One of the valves was abnormal but it. was not on the left side. The tricuspid valve had a flat firm vihite plaque about half a centimetre in diameter (fig. 1), which bistologically consists of organizing fibrin amd platelets but no organisms. This is a marantic non-bacterial thrombotic endocarditis, which we see in wasting diseases. The other valves were normal. The liver was congested and pale, and showed mild non-specific chronic inflammatory cell infiltration in the portal tracts microscopically. The biliary tree and pancreas were normal.

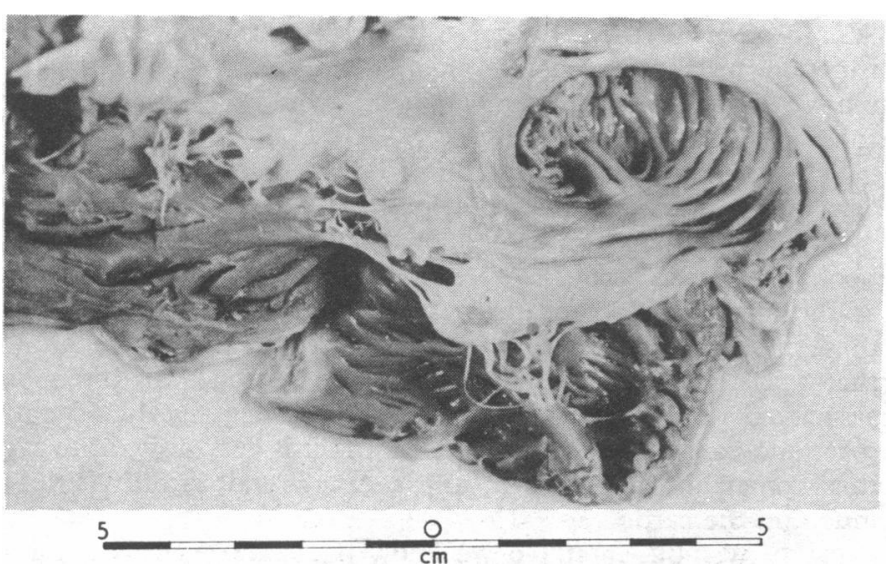

FIG. 1-Marantic vegetation (centre) on tricuspid valve.

The spleen was moderately enlarged and showed fibrinous adherence to the surrounding structures. There were small subcapsular infarcts and recent thrombosis in the appropriate vessels. I found no source for systemic emboli. Microscopically there was a busy grey pulp and the Malpighian bodies were blurred at the edges with fibrin and karyorhexis. This is a chronic process involving the central arterioles with deposition of immunoglobulin (fig. 2). A German study associates this with ischaemic tissue lesions, wasting infections, and the cachexia of cancer. ${ }^{1}$ The gastrointestinal tract was apparently normal. The kidneys showed the changes of benign hypertensive nephrosclerosis. The bladder was contracted and inflamed but she had had an indwelling catheter. The internal genitalia were atrophic and, apart from a cervical erosion, were normal.

At this stage the necropsy was apparently complete with still no satisfactory explanations. However, on mulling over the empty body, I noticed a slight swelling on the right side of the pelvis, over the obturator foramen. On exposing this

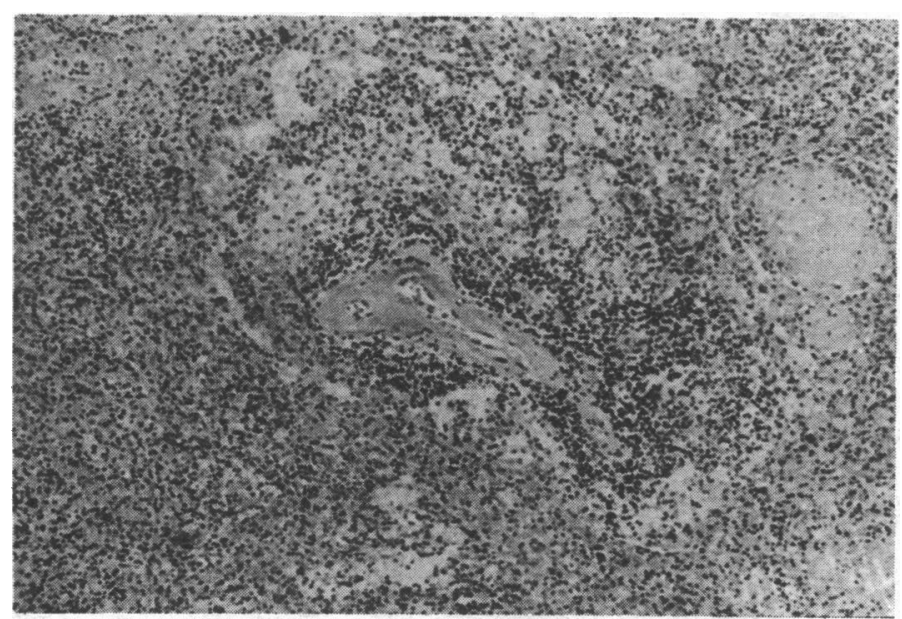

IT. 2-Spleen. Fibrinous dissolution of Malpighien body. ( $\times 14 \cdot 6)$.

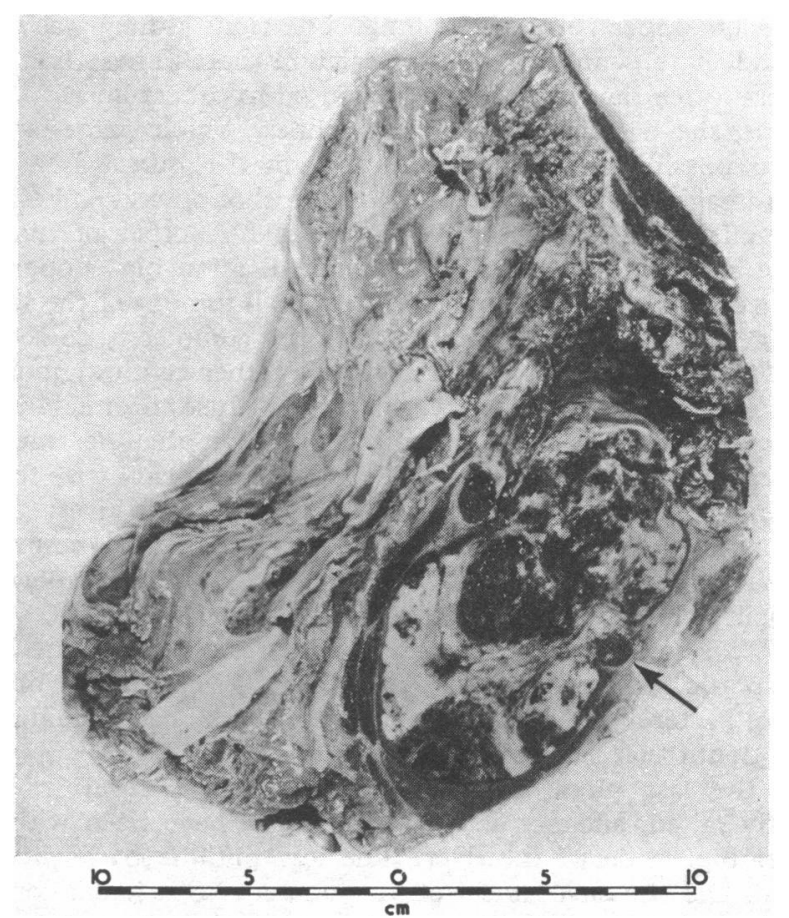

FIG. 3-Right hindquarter taken through sacro-iliac joint (top right) and sectioned to show dumb-bell tumour (bottom right), which lies below and behind femoral artery and bulges up through obturator foramen. Note erosion of inferior pubic ramus (arrow).

(fig. 3) it was found to be a dumbbell-shaped beefy red encapsulated tumour, bulging a little into the pelvis but with the main mass going outside it down into the root of the limb beneath the adductor muscles. It was related to the obturator nerve ( $L$ 2,3,4) which may account for the low backache though we would have expected the pain to have radiated to the knee. Histologically the tumour was necrotic centrally but in the surviving rim there was a very pleomorphic tumour, composed of large, often multinucleated cells with a rich eosinophilic cytoplasm, accompanied by an inflammatory infiltrate and fibrous capsule, and bone being eroded by osteoclasts (fig. 4). High power showed the cells in close-up (fig. 5) and further staining showed cross striations which gave the diagnosis as rhabdomyosarcoma. We have looked at this for several years now and wonder if some of the cells are Schwann cells and that this is one of the nerve sheath tumours in which rhabdomyosarcoma may develop. ${ }^{2}$ Another neural crest tumour, the meningioma, was also found in this body. She did not have von Recklinghausen's disease but the presence of both tumours may be more than fortuitous.

The final diagnosis was therefore: rhabdomyosarcoma possibly arising in a nerve sheath; meningioma; thrombotic nonbacterial endocarditis; fibrinous epicarditis; splenic infarction; terminal aspiration pneumonia; chronic bronchitis; benign hypertensive nephrosclerosis.

\section{Discussion}

DR. E. G. WADE (9): I don't find the tricuspid valve a satisfactory explanation for the loud systolic murmur. Was the mitral subvalvular apparatus normal and have you got histology of the papillary muscles, damage to which can cause functional mitral incompetence?

DR. BRANFOOT: I haven't got that histology but there was no evidence of dilatation of the ring.

SIR JOHN MCMICHARL: Which side was the fracture? Could the tumour have had anything to do with that?

DR. BAYLISS: No, it was the opposite side. In fact after all this we looked back at the $x$-ray films and there is one film which 


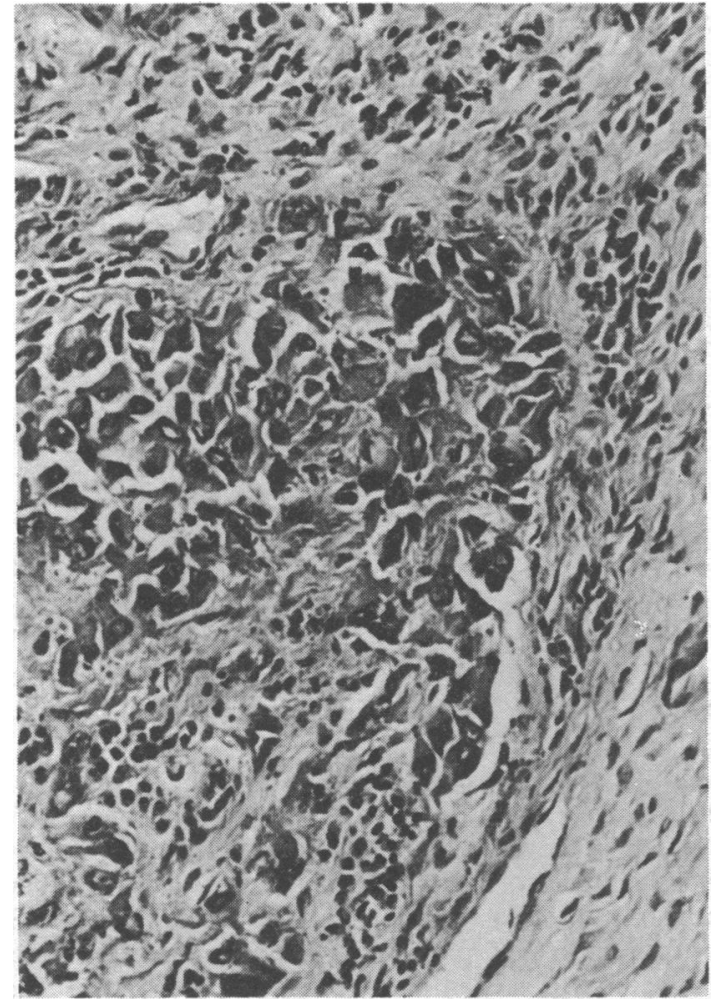

FIG. 4-Sarcoma evoking considerable inflammatory reaction. $(\times 43 \cdot 3)$.

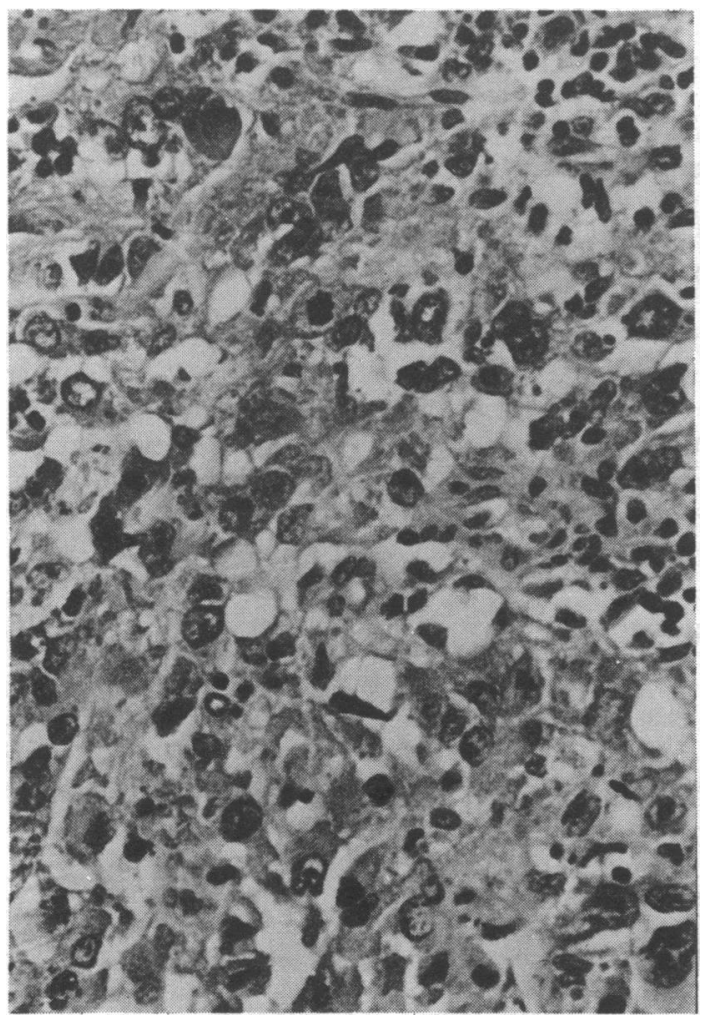

FIG. 5-High-power view of pleomorphic sarcoms with numerous mitoses. $(\times 68 \cdot 7)$.

shows the obturator foramina on both sides and it is abnormal in one corner on the right side. But even with hindsight we would never have made this diagnosis. Professor Booth, do you support the concept that the fever in this patient is the type of pyrexia you sometimes see in malignant disease, the nature of which we don't know?
PROFESSOR BOOTH: I would say it was-a prolonged fever unresponsive to any sort of therapy. I have not seen it in a patient with sarcoma but it is logical to assume it would happen.

PROFESSOR A. G. W. WHITFIELD (10): Can this diagnosis explain the hyperglycaemia and glycosuria of the last weeks of her illness? And would Dr. Branfoot tell us how to take her pericarditis ?

PROFESSOR BOOTH: I have no explanation for her diabetes other than she might have been a latent diabetic whose illness made it overt, unless she stopped secreting insulin because she stopped making protein. She had a low serum albumin and partially inhibited haemoglobin synthesis; tumours can do strange things to protein synthesis.

DR. BAYLISS: I think she must have been a latent diabetic. Latterly she stopped taking food by mouth and the nurses were trying to keep her calorie intake up intravenously with heavy carbohydrate loads, and this would be a factor promoting pancreatic exhaustion.

DR. BRANFOOT: Some soft tissue tumours are known to cause hypoglycaemia, and there are reports of hyperglycaemia occurring with fibrosarcoma of the lung. ${ }^{3}$ As for the pericarditis, she certainly was not uraemic. It could have been sympathetic from her lung infection but this was not sufficiently extensive. Could it have been due to a disturbance in her coagulation mechanism? Extensive reports on marantic endocarditis don't mention associated pericarditis."

DR. M. STEEL (11): Could you give us your views about her downward course and death?

DR. BAYLISs: I think we are wholly ignorant of the chemicals these malignant tissues produce. One day a real peptide chemist will define the "poisons" these tumours synthesize, causing mental confusion, cachexia, endocrine and biochemical disturbances.

This Conference was recorded and edited by Dr. W. F. Whimster.

\section{APPOINTMENTS OF SPEARERS}

(1) Professor C. C. Booth, M.D., F.R.C.P., Professor of Medicine, Royal Postgraduate Medical School, London.

(2) Dr. R. I. S. Bayliss, M.D., F.R.C.P., Consultant Physician, Westminster Hospital, London.

(3) Sir John Mcmichael, M.D., F.R.C.P., F.R.S., Emeritus Professor of Medicine, University of London.

(4) Dr. J. H. Walters, M.D., F.R.C.P., Consultant Physician, Hospital for Tropical Diseases, London.

(5) Dr. J. B. Harman, M.D., F.R.C.P., Consulting Physician, St. Thomas's Hospital, London.

(6) Dr. M. Nellen, M.D., F.R.C.P., Honorary Lecturer in Cardiology, Royal Postgraduate Medical School, London.

(7) Dr. D. W. Pugh, M.D., F.R.C.P., Physician, United Bath Hospitals.

(8) Dr. A. C. Branfoot, M.R.C.Path., F.R.C.S. Senior Lecturer in Morbid Anatomy and Honorary Consultant, Westminster Hospital, London.

(9) Dr. E. G. Wade, M.D., F.R.C.P., Consultant Cardiologist, Manchester Royal Infirmary.

(10) Professor A. G. W. Whitfield, M.D., F.R.C.P., Professor of Medicine, University of Birmingham.

(11) Dr. M. Steel, M.D., F.R.C.P., Consultant Physician, Grimsby Group of Hospitals.

\section{References}

1 Stutte, H. J., and Schtilter, E., Virchows Archiv Abteilung A., 1972, 356,

Woodruff, J. M., Chernik, N. L., Smith, M. C., Millett, W. B., and Foote, F. W., Cancer, 1973, 32, 426.

Turner, M. A., and Horne, C. H. W., British Youmal of Surgery, 1970,

57, 713.
Rosen, P., and Armstrong, D., American Fournal of Medicine, 1973, 54, 